\title{
Pulmonary vascular-bronchial interactions: acute reduction in pulmonary blood flow alters lung mechanics
}

\author{
I Schulze-Neick, D J Penny, G P Derrick, R Dhillon, M L Rigby, A Kelleher, A Bush, \\ A N Redington
}

\begin{abstract}
Background-Postoperative pulmonary hypertension in children after congenital heart surgery is a risk factor for death and is associated with severe acute changes in both pulmonary vascular resistance and lung mechanics.

Objective-To examine the impact of changes in pulmonary blood flow on lung mechanics in preoperative children with congenital heart disease, in order to assess the cause-effect relation of pulmonary vascular-bronchial interactions.

Design-Prospective, cross sectional study.

Setting-Cardiac catheterisation laboratory, general anaesthesia with mechanical ventilation. Interventions-Variation of pulmonary blood flow ( $\mathrm{Qp}$ ) by either balloon occlusion of an atrial septal defect before interventional closure, or by complete occlusion of the pulmonary artery during balloon pulmonary valvuloplasty for pulmonary valve stenosis.

Main outcome measures-Ventilatory tidal volume $(\mathrm{Vt})$, dynamic respiratory system compliance (Cdyn), respiratory system resistance (Rrs).

Results-28 occlusions were examined in nine patients with atrial septal defect (median age 9.5 years) and 22 in eight patients with pulmonary stenosis (median age 1.2 years). Normalisation of Qp during balloon occlusion of atrial septal defect caused no significant change in airway pressures and Rrs, but there was a small decrease in Vt (mean (SD): $9.61(0.85)$ to 9.52 (0.97) $\mathrm{ml} / \mathrm{kg}$; $\mathrm{p}<0.05)$ and Cdyn $\left(0.64(0.11)\right.$ to $\left.0.59(0.10) \mathrm{ml} / \mathrm{cm} \mathrm{H}_{2} \mathrm{O}^{\star} \mathrm{kg} ; \mathrm{p}<0.01\right)$. These changes were more pronounced when there was complete cessation of Qp during balloon valvuloplasty in pulmonary stenosis, with a fall in Vt $(9.71(2.95)$ to $9.32(2.84) \mathrm{ml} / \mathrm{kg} ; \mathrm{p}<0.05)$ and Cdyn $(0.72$ $(0.29)$ to $\left.0.64(0.26) \mathrm{ml} / \mathrm{cm} \mathrm{H}_{2} \mathrm{O}^{\star} \mathrm{kg} ; \mathrm{p}<0.001\right)$, and there was also an increase in $\mathrm{Rrs}(25.1$ (1.7) to $28.8(1.6) \mathrm{cm} \mathrm{H}_{2} \mathrm{O} /$ litre $\left.^{\star} \mathrm{s} ; \mathrm{p}<0.01\right)$. All these changes exceeded the variability of the baseline measurements more than threefold.

Conclusions-Acute changes in pulmonary blood flow are associated with simultaneous changes in lung mechanics. While these changes are small they may represent a valid model to explain the pathophysiological impact of spontaneous changes in pulmonary blood flow in clinically more critical situations in children with congenital heart disease.

(Heart 2000;84:284-289)
\end{abstract}

Keywords: pulmonary blood flow; lung mechanics; catheter intervention; cardiopulmonary interaction

Cardiothoracic Unit, Great Ormond Street Hospital for Children, Great Ormond Street, London WC1 3JN, UK I Schulze-Neick

D J Penny

G P Derrick

A N Redington

Department of

Paediatrics, The Royal

Brompton and

Harefield NHS Trust,

Sydney Street, London SW3 6NP, UK

R Dhillon

M L Rigby

A Bush

Department of

Anaesthesiology, The

Royal Brompton and

Harefield NHS Trust

A Kelleher

Correspondence to: Professor Redington email: reding@attglobal.net

Accepted 10 May 2000
Acute pulmonary hypertension is a separate risk factor for morbidity and mortality in children with congenital heart disease. ${ }^{1}$ The most obvious manifestations of this are pulmonary hypertensive crises. Desaturation, hypotension, and ventilatory difficulties are coincident with acute pulmonary vasoconstriction and lead to reduced transpulmonary blood flow, acute right ventricular decompensation, low cardiac output, and systemic hypotension. ${ }^{2}$

The change in pulmonary vascular resistance is intimately linked to a deterioration of pulmonary mechanical function. ${ }^{34}$ We have shown that patients with rebound pulmonary hypertension after withdrawal of nitric oxide treatment have a similar change in pulmonary mechanics. ${ }^{4}$ However, it remains unclear whether the acute reduction in pulmonary blood flow as such can cause a change in pulmonary mechanical function.

A clear delineation of the cause-effect relations of these pulmonary vascularpulmonary mechanical interactions could be crucial in understanding postoperative pulmonary hypertension and its treatment. Examina- tion of the effects of acute changes in pulmonary blood flow on lung mechanics without the confounding postoperative effects of open heart surgery would go some way to clarify these relations.

We therefore studied lung mechanics in children with congenital heart disease undergoing interventions in the cardiac catheter laboratory. Pulmonary blood flow was varied acutely by either obstruction of left to right blood shunting during interventional closure of an atrial septal defect, or by abolishing pulmonary artery blood flow during pulmonary balloon valvuloplasty.

\section{Methods}

The study included nine patients with atrial septal defect (ASD group; age range 1.1-28.9 years, median 9.5 years) and eight patients with pulmonary valve stenosis (PS group; age range 0.01-21.7 years, median 1.2 years). The study protocol was approved by our hospital research ethics committee, and written informed consent was obtained from the patient or the parents of each child. All patients were examined 
during general anaesthesia in the cardiac catheter laboratory. They were included in the study when there was either an isolated atrial septal defect or pulmonary valve stenosis without any additional intracardiac or vascular malformations.

All patients with atrial septal defect had important left to right shunts with a mean (SD) pulmonary to systemic blood flow ratio of 3.5 (0.9):1. In the patients with pulmonary valvar stenosis, the Doppler echocardiographic gradient measured over the stenotic pulmonary valve before intervention was 56.3 (19.7) $\mathrm{mm} \mathrm{Hg}$, and right ventricular systolic pressure was 72.3 (18.4) $\mathrm{mm} \mathrm{Hg}$ measured during cardiac catheterisation. After cardiac intervention, the right ventricular systolic pressure had decreased to 44.6 (22.5) $\mathrm{mm} \mathrm{Hg}$ $(\mathrm{n}=6, \mathrm{p}<0.001)$. None of the patients with pulmonary stenosis had evidence of right to left shunting or decreased cardiac output. Patients were excluded if there was a history of reactive airways disease, chronic lung disease, or any evidence of upper or lower respiratory tract infection.

VENTILATION AND ANAESTHETIC MANAGEMENT All patients were anaesthetised and intubated with a cuffed endotracheal tube. The cuff was inflated to a pressure below systemic arterial diastolic pressure. All patients were ventilated with a Servo 900C ventilator, delivering pressure controlled ventilation adjusted to provide a constant peak inspiratory pressure of $18-22 \mathrm{~cm} \mathrm{H}_{2} \mathrm{O}$ and a tidal volume of 9-11 ml/ $\mathrm{kg}$. The ventilator rate was adjusted so that end tidal carbon dioxide concentration ranged between 3.5 and $4.5 \mathrm{kPa}$. Anaesthesia was performed with intravenous propofol in adults, and was induced with gaseous servofluorane and then maintained with intravenous midazolam and fentanyl in the children. All were paralysed with vecuronium for the duration of the study.

\section{MEASUREMENTS}

Airway flow was measured with a double hot wire anemometer (Dräger Medical, Lübeck, Germany), a device which is linear from $0.5-10 \mathrm{l} / \mathrm{min}$, with a resolution of $0.1 \mathrm{l} / \mathrm{min}$ and an accuracy of $\pm 5 \%$. It was connected through an angled connector to the endotracheal tube. Airway pressure was measured using a micromanometer tipped catheter (Millar Instruments, Houston, USA) advanced into the endotracheal tube to just above its tracheal orifice. This device has a linear pressure response from -50 to $+300 \mathrm{~mm} \mathrm{Hg}$ with a frequency response of $0-20 \mathrm{~Hz}$ and an accuracy of $\pm 0.5 \%$. Flow and pressure measurements underwent two-point calibration. Ventilator settings remained unchanged thereafter.

To study the temporal relations between the interventional events and the recordings of pulmonary mechanics, we adapted a further micromanometer tipped catheter between the distal port of the balloon catheter and the syringe used for inflating and deflating the balloon.
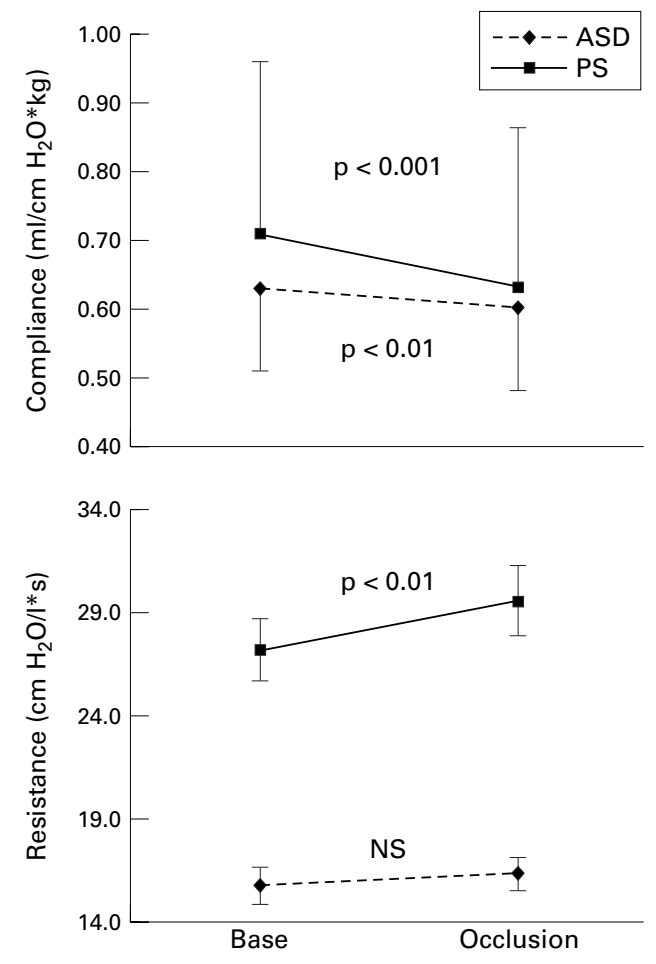

Figure 1 Dynamic respiratory system compliance $(\mathrm{ml} / \mathrm{cm}$ $\mathrm{H}_{2} \mathrm{O}^{\star} \mathrm{kg}$ ) and resistance ( $\mathrm{cm} \mathrm{H}_{2} \mathrm{O} /$ litre ${ }^{\star} s$ ) at baseline

("base") and interventional modification of pulmonary blood flow by balloon occlusion ("occlusion") of an atrial septal defect (ASD) and the pulmonary artery (PS).

Values are given as patient group mean; error bars $=S E M$.

MODIFICATION OF PULMONARY BLOOD FLOW BY CATHETER INTERVENTION

The effect of an acute reduction in pulmonary blood flow from an increased to a normal level was assessed in the patients with an atrial septal defect. The intervention consisted of occlusion of the defect with a latex sizing balloon, which was used to measure the size of the defect. Complete occlusion of the defect was confirmed by transoesophageal Doppler echocardiography. Measurements were taken immediately before and during the balloon occlusion of the defect. Thereafter the interventional procedure was continued as clinically required.

The effect of an acute complete abolition of pulmonary blood flow from normal levels was assessed in patients with pulmonary valve stenosis. The intervention consisted of balloon occlusion of the pulmonary artery during valvuloplasty of the pulmonary valve, using a balloon approximately $120-150 \%$ of the size of the pulmonary annulus, measured by echocardiography. The duration of inflation and deflation was approximately 10-30 seconds and was repeated one to three times as indicated clinically. Measurements were recorded throughout each inflation.

MEASUREMENT OF PULMONARY MECHANICS

Flow and pressure signals were digitised at 100 Hz (DT2801-A, Data Translation, Marlboro, Massachusetts, USA), stored on computer, and processed off-line (ANADAT, Jason Bates, Meakins Christie Laboratory, McGill University, Montreal, Canada), with flow signals being integrated to derive volume 
Table 1 Data on effects of acute changes in pulmonary blood flow on lung mechanics

\begin{tabular}{|c|c|c|c|c|c|}
\hline & & \multicolumn{2}{|c|}{ ASD occlusion $(n=9)$} & \multicolumn{2}{|c|}{ PS occlusion $(n=8)$} \\
\hline \multicolumn{2}{|c|}{ Age (years) } & \multicolumn{2}{|l|}{$\begin{array}{l}12.3(11.7) \\
\text { Median } 9.5\end{array}$} & \multicolumn{2}{|l|}{$\begin{array}{l}4.8(8.5) \\
\text { Median } 1.2\end{array}$} \\
\hline \multicolumn{2}{|c|}{ Haemodynamics } & \multicolumn{2}{|l|}{$(n=3)$} & \multicolumn{2}{|l|}{$(n=6)$} \\
\hline \multicolumn{2}{|c|}{ Qp:Qs ratio } & \multicolumn{2}{|l|}{$3.5(0.9): 1$} & \multicolumn{2}{|l|}{$1: 1$} \\
\hline \multicolumn{2}{|c|}{ RVSPpre (mm Hg) } & \multicolumn{2}{|l|}{$35.7(5.3)$} & \multicolumn{2}{|l|}{$72.3(18.4)$} \\
\hline \multicolumn{2}{|c|}{ RVSPpost (mm Hg) } & $32.2(7.9)$ & NS & $44.6(22.5)$ & $\mathrm{p}<0.001$ \\
\hline \multicolumn{6}{|c|}{ Tidal volume (ml/kg) } \\
\hline \multirow{2}{*}{\multicolumn{2}{|c|}{$\mathrm{m}_{\text {baseline }}(\%)$}} & \multicolumn{2}{|l|}{$9.61(0.85)$} & \multicolumn{2}{|l|}{$9.71(2.95)$} \\
\hline & & \multicolumn{2}{|l|}{$0.66(0.21)$} & \multicolumn{2}{|l|}{$0.90(0.64)$} \\
\hline \multicolumn{2}{|c|}{$\mathrm{m}_{\text {intervention }}$} & \multicolumn{2}{|l|}{$9.52(0.97)$} & \multicolumn{2}{|l|}{$9.32(2.84)$} \\
\hline \multicolumn{2}{|c|}{$z$ Score $_{\text {intervention }}$} & $2.04(0.31)$ & $\mathrm{p}<0.05$ & $3.06(0.86)$ & $\mathrm{p}<0.05$ \\
\hline \multicolumn{6}{|c|}{ Airway pressures (mm $\mathrm{Hg}$ ) } \\
\hline \multirow[t]{3}{*}{ Pmin } & $\mathrm{m}_{\text {baseline }}$ & \multicolumn{2}{|l|}{$2.31(1.70)$} & \multicolumn{2}{|l|}{$2.40(1.20)$} \\
\hline & $\begin{array}{l}\mathrm{CV}_{\text {baseline }}(\%) \\
\mathrm{m}_{\text {intervention }}\end{array}$ & $\begin{array}{l}11.90(2.54) \\
2.32(1.80)\end{array}$ & & $\begin{array}{l}16.90(7.80) \\
1.90(1.00)\end{array}$ & \\
\hline & $\mathrm{z} \mathrm{Score}_{\text {intervention }}$ & $0.35(0.21)$ & NS & $0.60(0.23)$ & $\mathrm{p}<0.01$ \\
\hline$P \max$ & $\mathrm{m}_{\text {baseline }}$ & $\begin{array}{l}20.6(2.9) \\
1.23(0.23)\end{array}$ & & $\begin{array}{l}18.2(3.0) \\
2.22(0.86)\end{array}$ & \\
\hline & $\begin{array}{l}C V_{\text {baseline }}(\%) \\
\mathrm{m}_{\text {intervention }}\end{array}$ & $20.8(3.1)$ & & $19.2(3.3)$ & \\
\hline & $\mathrm{z}$ Score $_{\text {intervention }}$ & $1.79(1.17)$ & NS & $1.45(0.40)$ & $\mathrm{p}<0.01$ \\
\hline$P_{0}$ & $\mathrm{~m}_{\text {baseline }}$ & $4.30(0.30)$ & & $4.40(0.40)$ & \\
\hline & $\mathrm{CV}_{\text {baseline }}(\%)$ & $8.54(3.21)$ & & $9.25(4.73)$ & \\
\hline & $\mathrm{m}_{\text {intervention }}$ & $4.10(0.50)$ & & $2.30(0.70)$ & \\
\hline & z Score intervention $_{\text {. }}$ & $2.42(1.45)$ & NS & $4.29(1.83)$ & $\mathrm{p}<0.01$ \\
\hline Dynan & compliance (ml & $\left.\mathrm{H}_{2} \mathrm{O}{ }^{\star} \mathrm{kg}\right)$ & & & \\
\hline $\mathrm{m}_{\text {bas }}$ & & $0.64(0.11)$ & & $0.72(0.29)$ & \\
\hline $\mathrm{CV}_{\mathrm{b}}$ & ne $(\%)$ & $1.97(0.47)$ & & $2.33(0.76)$ & \\
\hline $\mathrm{m}_{\text {inte }}$ & & $0.59(0.10)$ & & $0.64(0.26)$ & \\
\hline $\mathrm{z} \mathrm{Sc}$ & intervention & $3.02(1.59)$ & $\mathrm{p}<0.01$ & $3.68(0.62)$ & $\mathrm{p}<0.001$ \\
\hline Airway & esistance $\left(\mathrm{cm} \mathrm{H}_{2}\right.$ & $\left.r e^{\star} s\right)$ & & & \\
\hline $\mathrm{m}_{\text {bas }}$ & & $15.70(0.90)$ & & $25.10(1.70)$ & \\
\hline $\mathrm{CV}_{\mathrm{b}}$ & ne $(\%)$ & $2.72(1.26)$ & & $6.57(2.23)$ & \\
\hline $\mathrm{m}_{\text {inte }}$ & & $16.40(0.90)$ & & $28.80(1.60)$ & \\
\hline $\mathrm{z} \mathrm{Sc}$ & intervention & $0.84(0.76)$ & NS & $3.07(1.51)$ & $\mathrm{p}<0.01$ \\
\hline
\end{tabular}

The values from multiple measurements were averaged for each patient, and then by patient group. Thus the resulting value 1 ( \pm value 2 ) given is the mean and its standard deviation of all averaged values per patient (that is, 9 in the ASD group, and 8 in the PS group).

ASD, atrial septal defect; $\mathrm{CV}_{\text {baseline }}$, coefficient of variation of the baseline measurement; $\mathrm{m}_{\text {baseline }}$, mean value at baseline; $\mathrm{m}_{\text {intervention, }}$ mean value during intervention; Pmax, $\mathrm{Pmin}$, and $\mathrm{P}_{0}$ maximum, minimum airway pressure, and calculated end expiratory airway pressure; PS, pulmonary stenosis; Qp:Qs ratio, ratio of pulmonary to systemic blood flow; RSVP, right ventricular

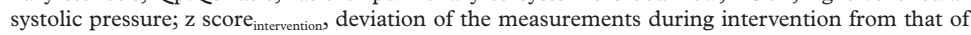
the baseline, expressed as a multiple of the baseline variability.

change. The equation of motion for a single compartment lung model was solved using multiple linear regression, ${ }^{5}$ and total respiratory system resistance (Rrs) and dynamic compliance (Cdyn) were then computed using the equation: Paw $=$ Ers ${ }^{\star} \mathrm{V}+\mathrm{Rrs}{ }^{\star} \mathrm{V} / \mathrm{s}+\mathrm{P}_{0}$ where Paw is airway pressure, Ers is elastance ( $=1 /$ compliance $), \mathrm{V}$ is volume, $\mathrm{V} / \mathrm{s}$ is flow, and $\mathrm{P}_{0}$ is alveolar pressure reflecting auto-PEEP (positive end expiratory pressure) or inadvertent PEEP. ${ }^{5}{ }^{6}$ Single breaths were discarded when the coefficient of determination was less than 0.95 . We analysed the whole respiratory cycle, as this resulted in the lowest standard deviations of measured variables. ${ }^{6}$

DATA EVALUATION AND STATISTICAL ANALYSIS Recordings of pulmonary mechanics were related to the recordings of the pressure of the balloon catheter used for the intervention, so that the beginning and end of the acute intervention during that particular measurement could be unequivocally identified (fig 1). For each measured or calculated variable, the following calculations were performed.

- For each individual measurement, the mean value $(\mathrm{m})$ and standard deviation $(\mathrm{SD})$ at "baseline", and the mean value during "intervention" were derived from 15 breaths before the intervention, and from the last three breaths during the intervention ( $\mathrm{m}_{\text {base }}$ line, $\mathrm{SD}_{\text {baseline }}$, and $\left.\mathrm{m}_{\text {intervention }}\right)$. Then the variability at baseline was expressed as the coefficient of variation $\left(\mathrm{CV}_{\text {baseline }}=\mathrm{SD}_{\text {baseline }}\right.$ / $\mathrm{m}_{\text {baseline }}(\%)$ ), and the deviation from the baseline during the intervention as the $\mathrm{z}$ score $_{\text {intervention }}\left(\left[\mathrm{m}_{\text {baseline }}-\mathrm{m}_{\text {intervention }}\right] / \mathrm{SD}_{\text {baseline }}\right)$. This therefore resulted in 28 number groups for the measurements in the ASD group and 22 in the PS group.

- The values from multiple measurements were averaged, resulting in one value for $\mathrm{m}_{\text {baseline }}, \mathrm{CV}_{\text {baseline }}, \mathrm{m}_{\text {intervention }}$, and $\mathrm{z}$ score intervention of that variable for each patient.

- The data were further reduced by averaging by patient group. Thus the resulting value 1 ( \pm value 2 ) given in table 1 is the mean and its standard deviation of all averaged values for each patient (that is, nine in the ASD group, and eight in the PS group).

- The significance of the changes during intervention was assessed by calculating the symmetrical percentage difference between the patient's averaged baseline and intervention values $\left(100^{\star} \log _{\mathrm{e}}\left[\mathrm{m}_{\text {baseline }}\right]-\right.$ $\left.100^{\star} \log _{\mathrm{e}}\left[\mathrm{m}_{\text {intervention }}\right]\right){ }^{7}$ All symmetrical percentage differences were then tested for each patient group against the null hypothesis using Student's $t$ test with eight (atrial septal defect group) and seven (pulmonary stenosis group) degrees of freedom. A value of $\mathrm{p}<0.05$ was considered significant.

\section{Results}

BASELINE VALUES

Twenty eight occlusions of atrial septal defects and 22 occlusions of the pulmonary artery were recorded. The mean (SD) tidal volumes in both patient groups were similar, at 9.61 (0.85) and $9.71(2.95) \mathrm{ml} / \mathrm{breath}$, with a low coefficient of variation $(<1 \%)$. Baseline values for dynamic lung compliance were slightly lower in the ASD group (0.64 (0.11) $v 0.72$ (0.29) $\left.\mathrm{ml} / \mathrm{cm} \mathrm{H}_{2} \mathrm{O}, \mathrm{p}<0.01\right)$. Airway resistance decreased appropriately according to age, as the ASD group was older than the PS group (15.7 (0.9) v $25.1 \quad$ (1.7) $\mathrm{cm} \mathrm{H}_{2} \mathrm{O} /$ litre $^{\star} \mathrm{s}$, $\mathrm{p}<0.001)$, and were within published values for this age. ${ }^{8}$

NORMALISING PULMONARY BLOOD FLOW DURING ATRIAL SEPTAL DEFECT OCCLUSION

During occlusion of the defect, airway pressures and airway resistance did not change significantly (table 1), but there was a reversible decrease in tidal volume (to $9.52(0.97) \mathrm{ml} / \mathrm{kg}$; $\mathrm{p}<0.05$ ) and dynamic compliance (to 0.59 (0.10) $\mathrm{ml} / \mathrm{cm} \mathrm{H}_{2} \mathrm{O}^{\star} \mathrm{kg}$; $\mathrm{p}<0.01$ ) (fig 1). These changes exceeded the variability of the baseline measurements by two- to threefold and were highly significant (table 1). Calculated alveolar end expiratory pressure $\mathrm{P}_{0}$ remained unchanged. Right ventricular systolic pressures before and after interventional closure of the defect were unchanged (35.7 (5.3) and 32.2 (7.9) $\mathrm{mm} \mathrm{Hg}$, resp $(\mathrm{n}=3)$ ). 

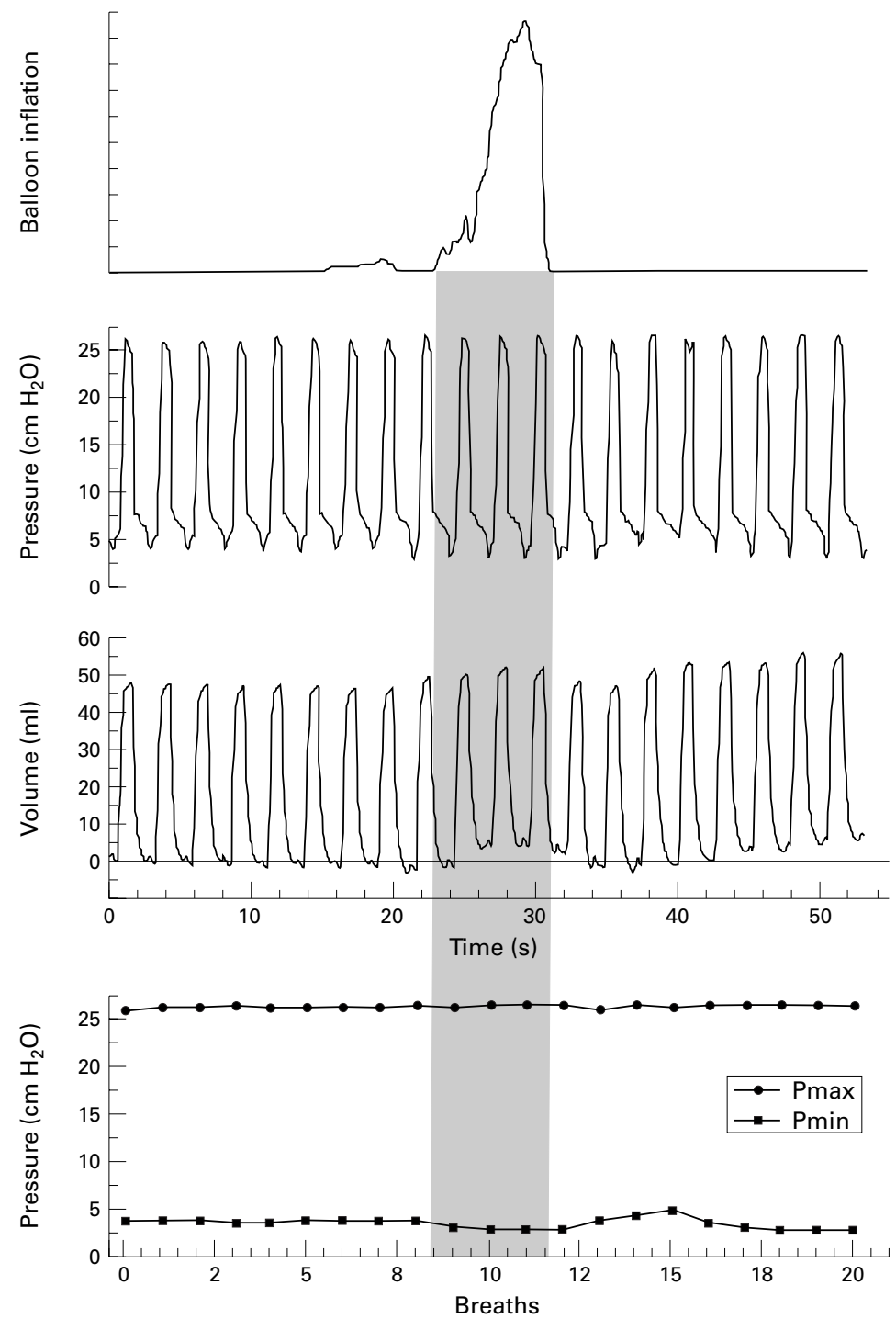

Figure 2 Balloon inflation pressure (without units), airway pressure ( $\mathrm{cm}_{2} \mathrm{O}$ ), tidal volume (ml), and maximum (Pmax) and minimum (Pmin) airway pressures for each breath during pulmonary valvuloplasty. The tracings represent the original recordings of a patient during pulmonary balloon valvuloplasty (shaded bar) while the balloon was positioned and slightly predilated, and then inflated, thus occluding the pulmonary artery.

ACUTE CESSATION OF PULMONARY BLOOD FLOW DURING PULMONARY VALVULOPLASTY

The dynamic changes are graphically illustrated in figs 2 and 3. During occlusion of the pulmonary artery, there was a reduction in tidal volume (to $9.32(2.84) \mathrm{ml} / \mathrm{kg}$; $\mathrm{p}<0.05$ ) and of dynamic respiratory system compliance (to 0.64 (0.26) $\mathrm{ml} / \mathrm{cm} \mathrm{H}_{2} \mathrm{O}^{\star} \mathrm{kg} ; \mathrm{p}<0.001$ ). These changes exceeded the variability of the baseline measurement at least threefold and were highly significant (table 1). There also was an increase in airway resistance (to 28.8 (1.6) $\mathrm{cm} \mathrm{H}_{2} \mathrm{O} /$ litre ${ }^{\star} \mathrm{s}$; p < 0.01) (table 1, fig 1) and a fall in calculated alveolar end expiratory pressure $\mathrm{P}_{0}$ from $4.4(0.4)$ to $2.3(0.7) \mathrm{mm} \mathrm{Hg}$ $(\mathrm{p}<0.01)$.

\section{Discussion}

This is the first study examining the effects of an acute reduction in pulmonary blood flow on pulmonary mechanics in children. These effects were small but consistent, significant, reproducible, and transient.
In our patients, reduction in pulmonary blood flow to a normal level during abolition of left to right shunting by balloon occlusion of an atrial septal defect had little impact on lung mechanics. Although highly significant, there was only a small reduction in dynamic compliance and tidal volume, with no change in airway resistance. This is in agreement with clinical $^{9}$ and animal studies, ${ }^{10}$ which have shown that lung mechanics are not influenced by large variations in pulmonary blood flow if pulmonary arterial and left atrial pressures are kept constant.

In contrast, cessation of pulmonary blood flow during pulmonary valvuloplasty had a major impact on lung mechanics. There was an abrupt and important increase in airway resistance, a fall in lung compliance, and a decrease in tidal volume. Figures 2 and 3 show the dynamic nature of these changes. Although tidal volume ultimately falls during the course of the occlusion, there is an initial rise in inspired volume, and an increase in lung gas volume. This is almost certainly a compensatory mechanism, replacing the volume of blood passing from the pulmonary vasculature into the left heart and ejected out of the thorax. This increase in lung volume probably does not reflect "air trapping" as the calculated $\mathrm{P}_{0}$ fell. ${ }^{11}$

The determination of calculated end expiratory pressure $\left(\mathbf{P}_{0}\right)$ using the multiple linear regression method has been extensively validated $^{11}$ using the same methods of data acquisition and processing as in our study, both in open chest dogs with pharmacologically induced changes of lung mechanics and in children during cardiothoracic surgery. It proved to be a robust method with excellent agreement of $\mathrm{P}_{0}$ and measured alveolar pressure, even in the presence of non-linearities of pressure-volume relations. ${ }^{6}$ This is important as the observed changes in dynamic compliance in the presence of increased tidal volumes could be attributed to shifts of the pressurevolume loop to the left. On manually examining single pressure-volume recordings, no indication of overdistension or non-linearity ("banana shape" ") was found. The presence of possible relative overdistension was also evaluated by calculating respiratory mechanics with a volume dependent single compartment model. ${ }^{13}$ The contribution of the volume dependent compliance $(\% \mathrm{E} 2)$ to total respiratory compliance was less than $1 \%$ in all breaths, thus ruling out significant overdistension.

The change in airway resistance is more intriguing, and probably reflects a direct anatomical as well as physiological relation between the lung vasculature and the airways. It is unlikely that reduced pulmonary blood flow significantly reduces alveolar carbon dioxide levels, but bronchoconstriction caused by diminished carbon dioxide influx into the pulmonary vasculature cannot be excluded. We have measured end tidal carbon dioxide and it fell synchronously with the intervention. The duration was short lived and the decrease was small (about 2\%), and thus appears not to be clinically relevant. Furthermore, it has been 

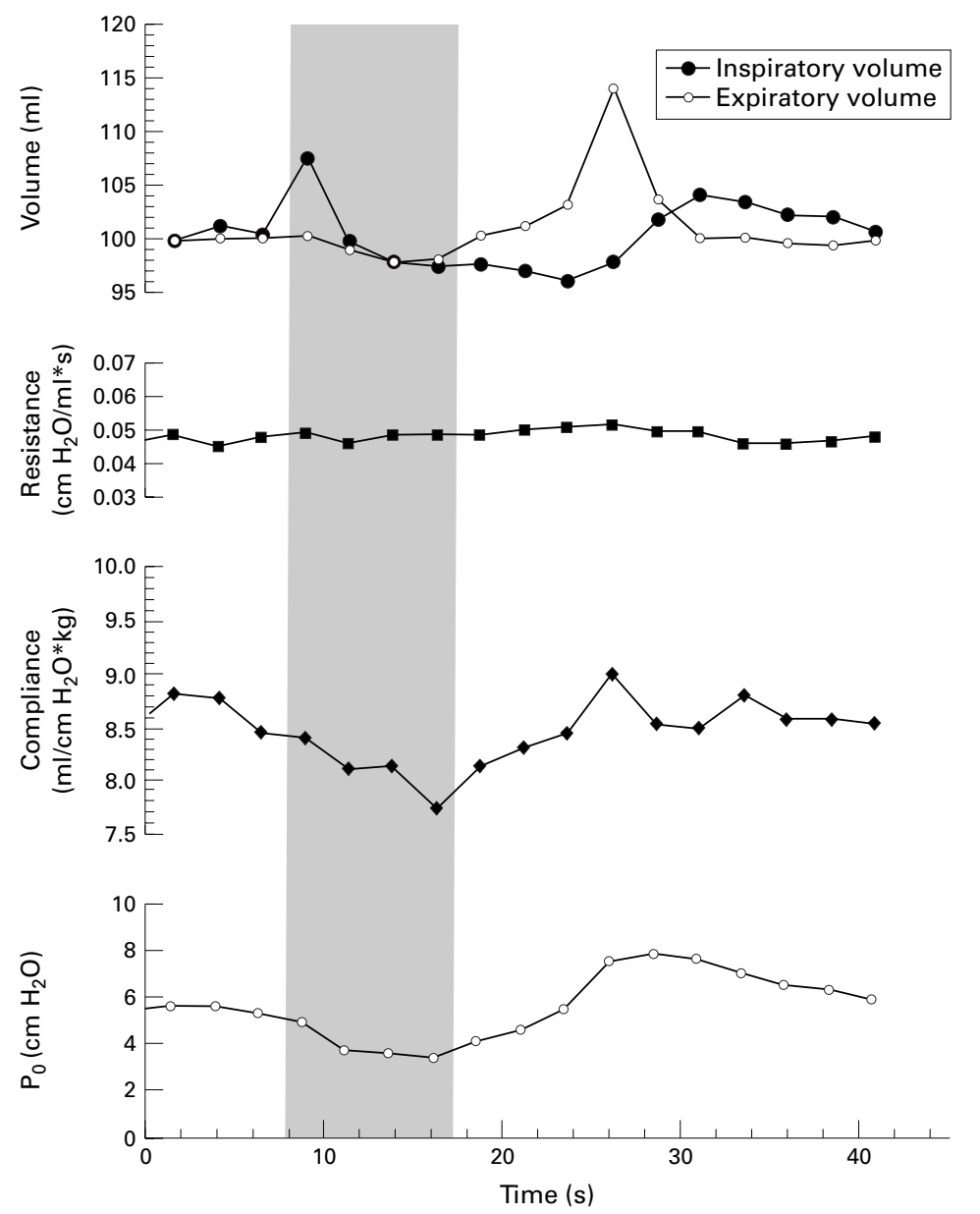

Figure 3 Synopsis of calculated respiratory mechanics during pulmonary valvuloplasty in one patient. Inspiratory and expiratory volume, respiratory system resistance ( $\mathrm{cm}$ $\mathrm{H}_{2} \mathrm{O} /$ litre $\left.{ }^{\star} \mathrm{s}\right)$ and compliance $\left(\mathrm{ml} / \mathrm{cm} \mathrm{H}_{2} \mathrm{O}^{\star} \mathrm{kg}\right)$ together with calculated end expiratory airway pressure $\left(P_{0}\right)$ for each breath are simultaneously illustrated during pulmonary balloon dilatations (shaded bar), where pulmonary artery occlusion occurred.

suggested that at least six minutes of hypocapnic hyperventilation are required ${ }^{14}$ in order to produce reproducible bronchoconstriction.

However, there is increasing evidence to suggest that the small peribronchiolar vessels serve an erectile function, maintaining airway patency. Variations in pulmonary artery pressure caused in dogs that had a balloon catheter in the left atrium to simulate cardiogenic pulmonary oedema showed a close correlation with compliance and lung gas volume, ${ }^{1516}$ probably because of engorgement of the alveolar capillary vessels. In contrast, variations in pulmonary blood flow without changes of pulmonary artery pressure did not cause changes in respiratory mechanics. ${ }^{9}$ However, our data show that pulmonary mechanics do respond to a pronounced and isolated decrease in pulmonary blood flow. In one animal study, ${ }^{17}$ occlusion of one pulmonary artery led to an ipsilateral decrease in lung compliance with diversion of tidal volume to the contralateral lung, and in another ${ }^{18}$ complete exsanguination of the lungs led to decreased lung distensibility. Balloon occlusion of the main pulmonary artery in otherwise normal children will lead to a prompt cessation of pulmonary blood flow and reduction in pulmonary arterial pressure. Our findings of increased airway resistance in these patients, but not in the atrial septal defect occlusion group (where pulmonary blood flow was reduced but maintained), is consistent with a loss of airway calibre secondary to the collapse of small vessels during an acute reduction in pulmonary blood flow.

These findings may contribute to our understanding of one of the most puzzling phenomena in the postoperative care of children with congenital heart disease. Postoperative pulmonary hypertensive crises are clinically associated with stiff, often unventilatable, lungs. These episodes reflect a complex interplay of changing haemodynamics and lung function, with superimposition of the neurohumoral effects of cardiopulmonary bypass. Our findings of increased lung resistance and decreased compliance with decreased pulmonary blood flow may in part explain the changes that occur during these events. Clearly, however, other mechanisms are involved, as the magnitude of these changes during pulmonary hypertensive crises is much greater. Nonetheless, the concept supported by both the data from this study and our previous findings, ${ }^{4}$ that an acute reduction in pulmonary blood flow is associated with a picture of acute ventilatory changes, may have more widespread implications for the management of children in the postoperative cardiac intensive care unit. Further studies of this relation and its implications are needed.

\section{CONCLUSIONS}

We have shown a direct relation between pulmonary blood flow and lung mechanics in children with congenital heart disease. Our data may help in the understanding of these co-related phenomena in other patient groups and allow a more focused assessment of their causation and treatment in the future.

We acknowledge the support of the SPARKS charity (No We acknowledge the support of the SPARKS charity (No his detailed statistical advice during the preparation of the his detailed
manuscript.

1 Rizzoli G, Mazzucco A, Maizza F, et al. Does Down syndrome affect prognosis of surgically managed atrioventricular canal defects? [see comments]. $\mathcal{F}$ Thorac Cardiovasc Surg 1992;104:945-53.

2 Hopkins RA, Bull C, Haworth SG, et al. Pulmonary hypertensive crises following surgery for congenital heart defects in young children. Eur f Cardiothorac Surg 1991;5:628-34.

3 Schindler MB, Bohn DJ, Bryan AC, et al. Increased respiratory system resistance and bronchial smooth muscle hypertrophy in children with acute postoperative pulmonary hypertension. Am $\mathcal{F}$ Respir Crit Care Med 1995;152:134752 .

4 Schulze-Neick I, Werner H, Penny DJ, et al. Acute ventilatory restriction in children after weaning off inhaled ventilatory restriction in children after weaning off inhaled
nitric oxide: relation to rebound pulmonary hypertension. nitric oxide: relation to rebound pulm

5 Bates J, Shardonofsky F, Stewart D. The low-frequency dependence of respiratory system resistance and elastance in normal dogs. Respir Physiol 1989;78:369-82.

6 Lanteri CJ, Kano S, Nicolai T, et al. Measurement of dynamic respiratory mechanics in neonatal and pediatric intensive care: the multiple linear regression technique. Pediatr Pulmonol 1995;19:29-45.

7 Cole TJ. Sympercents: symmetric percentage differences on

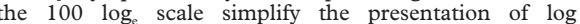
transformed data. Stat Med In press.

8 Lanteri C, Sly P. Changes in respiratory mechanics with age. f Appl Physiol 1993;74:369-78.

9 Bancalari E, Jesse MJ, Gelband $\mathrm{H}$, et al. Lung mechanics in congenital heart disease with increased and decreased pulmonary blood flow. $\mathcal{F}$ Pediatr 1977;90:192-5.

10 Uhlig T, Wildhaber JH, Eber E, et al. Vagal reflex is not responsible for changes in airway and lung tissue mechanics due to vascular engorgement in young piglets. Pediatr Res 1997;42:533-8. 
11 Nicolai T, Lanteri C, Freezer N, et al. Non-invasive determination of alveolar pressure during mechanical ventilation. Eur Resp f 1991;4:1275-83.

12 Nikischin W, Gerhardt T, Everett R, et al. A new method to analyze lung compliance when pressure-volume relationship is nonlinear. Am $\mathcal{F}$ Respir Crit Care Med 1998;158: $1052-60$

13 Kano S, Lanteri CJ, Duncan AW, et al. Influence of nonlinearities on estimates of respiratory mechanics using multilinear regression analysis [published errata appear in $\mathcal{7} A p p l$ Physiol 1995;78(3) and 1995;8(6)]. F Appl Physiol 1994;77: 1185-97.

14 Argyros GJ, Roach JM, Hurwitz KM, et al. Eucapnic voluntary hyperventilation as a bronchoprovocation technique: development of a standardized dosing schedule in asthmatics. Chest 1996;109:1520-4.
15 Borst HG, Berlund E, Whittenberger JL, et al. The effect of pulmonary vascular pressures on the mechanical properties of the lungs of anesthetized dogs. F Clin Invest 1957;36: 1708-14.

16 Gray BA, McCaffree DR, Sivak ED, et al. Effect of pulmonary vascular engorgement on respiratory mechanics in the dog. I Appl Physiol Respir Environ Exerc Physiol 1978;45: 119-27.

17 Simon B, Tsuzaki K, Venegas JG. Changes in regional lung mechanics and ventilation distribution after unilateral pulmonary artery occlusion. I Appl Physiol 1997;82: 882-91.

18 Colebatch H, Berend N, Maccioni F. Effect of the chest wall and blood volume on pulmonary distensibility. F Appl Physiol 1992;72:186-93.

\section{Coronary sinus ostial atresia with persistent left superior vena cava connected with atrial septal defect}

A 51 year old man with chest discomfort was diagnosed at echocardiography with atrial septal defect. A persistent left superior vena cava (PLSVC) was found incidentally during preoperative cardiac catheterisation. Direct injection of contrast media into the PLSVC (left) showed that it filled the coronary sinus (large arrowhead) then the coronary veins (small arrowheads), that the coronary sinus did not communicate with the right atrium, and that the coronary venous flow entered the right atrium by the PLSVC, the innominate vein, and the right superior vena cava. Three dimensional computed tomography (CT) (right) showed the small PLSVC (arrowheads), the diameter of which was $4 \mathrm{~mm}$ at the midportion, extending from the coronary sinus to the innominate vein (IV). Moderate enlargement

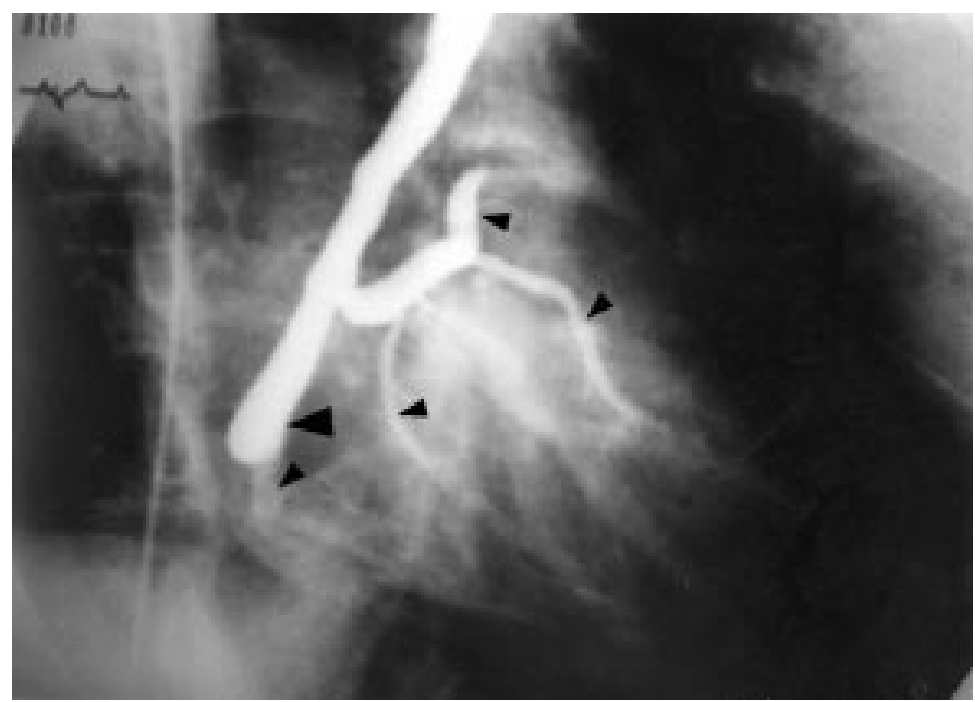

of the right ventricle (RV) with a prominent pulmonary artery (PA) is shown (AA, ascending aorta; LV, left ventricle; ARSA, aberrant right subclavian artery). The patient underwent surgical treatment for closure of the atrial septal defect, during which right atrial ostial atresia of the coronary sinus was confirmed.

Thirty six cases of atresia of the coronary sinus ostium with PLSVC have been previously reported. However, to our knowledge, this is the first reported three dimensional CT image of a small PLSVC associated with atrial atresia of the coronary sinus.

H ITO

H TAMURA Y ITO

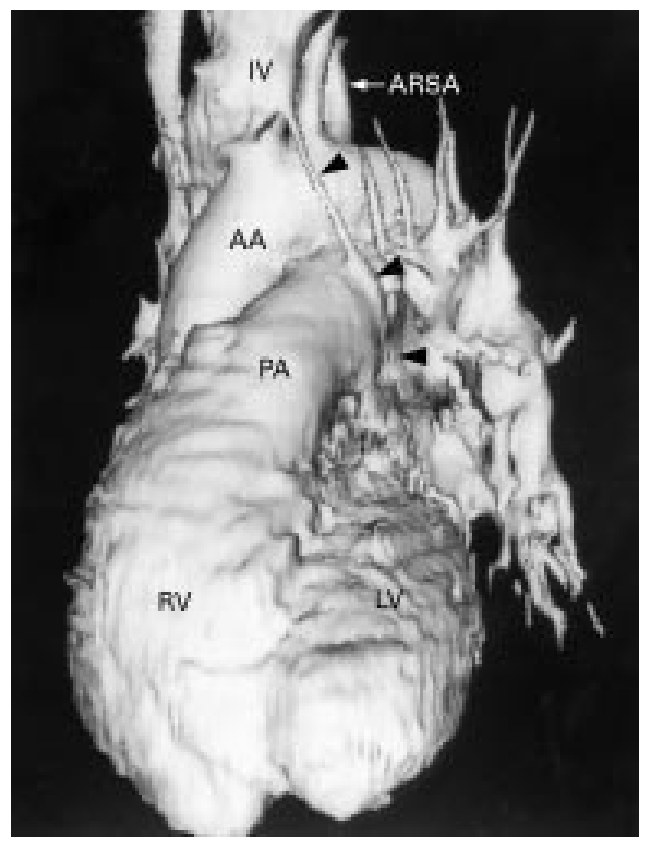

